\title{
A Numerical Study of Microphysical Processes in the 21 June 1991 Northern Taiwan Mesoscale Precipitation System
}

\author{
Hsin-Mu Lin ${ }^{1}$ and Pao K. Wang ${ }^{1}$
}

(Manuscript received 17 September 1996, in final form 30 September 1997)

\begin{abstract}
A three-dimensional, time-dependent, non-hydrostatic model is used to simulate the microphysical process in a convective precipitation system developed in the northern Taiwan. This simulation uses the hail parameterization model (HPM) version of the Wisconsin Dynamical/Microphysical Model (WISCDYMM), in which the precipitation hydrometeors are assumed to follow exponential size distribution, while cloud water and cloud ice are assumed to be monodispersed. The simulation is carried out for 120 minutes. The results exhibit key dynamic and thermodynamic features characteristic of the observed system, including an abrupt rainfall, a cold pool and split cell developing as system propagates. However, the orographic effect is not simulated here.

Integrated hydrometeor mass for the entire domain shows that about $\mathbf{5 0 \%}$ hydrometeor mass is in ice phase, with graupel and hail the most predominant type. The other $50 \%$ are contributed almost entirely by rain water. The total mass of rain, graupel and hail increase rapidly as system intensifies, while the total mass of ice and snow increase much more slowly and remain fairly steady as shown by time evolution of the hydrometeors. After 40 minutes, the percentage mass of each hydrometeor type in the domain seems to reach a quasi-steady state even though the total mass keeps growing. Production and depletion curves of microphysical processes for each hydrometeor type indicate that rain primarily comes from the shedding of liquid layer and melting of graupel and hail. Snow is primarily initiated by Bergeron-Findeisen process and accretion of rain droplet by cloud ice, and grows predominately from the Bergeron-Findeisen process. Hail and graupel are primarily initiated through rain-snow collision and deposition of water vapor, and grow mainly by accretion by rain and cloud water. The main depletion mechanism of rain is the accretion by graupel and hail for rain. Melting and shedding to form rain drops is the largest depletion process of graupel and hail.
\end{abstract}

\footnotetext{
${ }^{1}$ Department of Atmospheric and Oceanic Sciences, University of Wisconsin-Madison, Madison, Wisconsin, USA
} 


\section{(Key words: Hail parameterization model, Precipitation hydrometeors, Microphysical processes)}

\section{INTRODUCTION}

In the early afternoon of 21 June 1991, a convective precipitation system poured down more than $120 \mathrm{~mm}$ of rain in Taipei in 3 hours with hourly maximum at $94 \mathrm{~mm}$ (Jou, 1994). The case caught our attention not only because it caused a severe flash flood in the populated metropolitan area in Taiwan, but also it provides an opportunity to study the microphysical processes of the precipitation system in the subtropical area of East Asia.

Observations have shown for some time that the microstructure of atmospheric clouds and precipitation highly depends on the temperature, humidity, and continentality of the environment (Pruppacher and Klett, 1978). For the case of mid-latitude continental regions, it is known that ice-phase physics play a primary role in the initiation and production of precipitation in convective cloud (Johnson et al., 1993, 1994). On the other hand, it is clear whether or not this is so in low-latitude areas (Kruger et al., 1995, Tao et al., 1991, MacCumber et al., 1991). This study provides us an opportunity to examine the microphysical features of a subtropical convective storm by using a numerical model to investigate the various cloud microphysical processes that lead to the production and depletion of precipitation in the convective

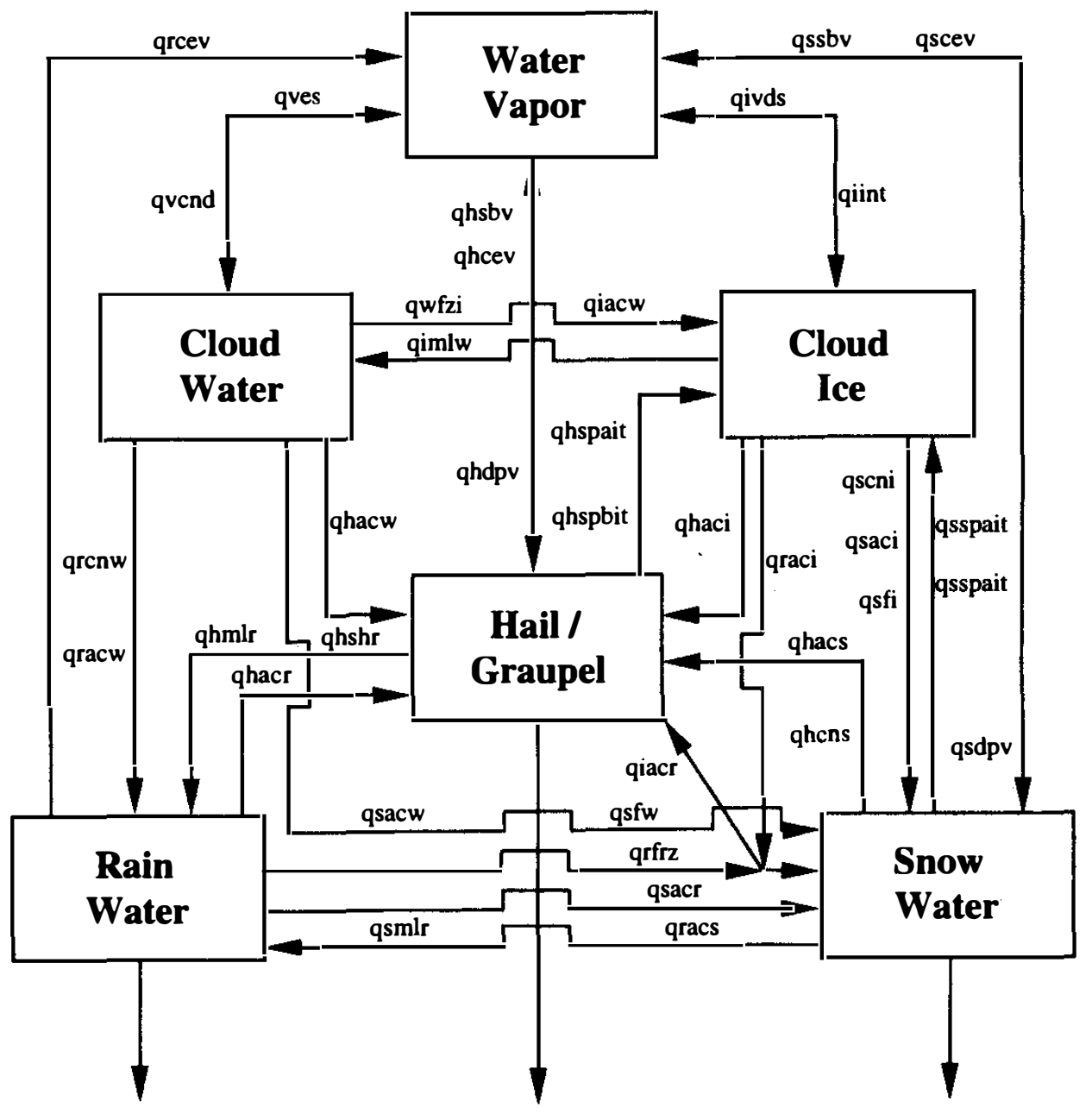

Fig. 1. Block diagram of the microphysical processes implemented in the WISCDYMM. 
Table 1. Definition of symbols for microphysical processes shown in Figure 1.

\begin{tabular}{|l|l|}
\hline Acronym & \multicolumn{1}{|c|}{ Process } \\
\hline qhaci & Accretion of cloud ice by hail \\
qhacr & Accretion of rain by hail \\
qhacs & Accretion of snow aggregates by hail \\
qhacw & Accretion of cloud water by hail \\
qhcev & Condensation/Evaporation of vapor to/from wet hail \\
qhens & Autoconversion of snow to hail \\
qhdpv & Vapor deposition to hail \\
qhmlr & Melting of hail to rain \\
qhsbv & Vapor sublimation from hail \\
qhshr & Rain water shed from hail \\
qhspait & Secondary production I of cloud ice from hail \\
qhspbit & Secondary production II of cloud ice from hail \\
qiacr & Accretion of rain by ice to form snow or hail \\
qiacw & Accretion of cloud water by cloud ice \\
qiint & Nucleation of pristine cloud ice \\
qimlw & Melting of cloud ice to cloud water \\
qivds & Vapor Deposition/Sublimation to/from cloud ice \\
qraci & Accretion of cloud ice by rain to form snow or hail \\
qracs & Accretion of snow by rain to form snow or hail \\
qracw & Accretion of cloud water by rain \\
qrcev & Evaporation of rain \\
qrcnw & Autoconversion of cloud water to rain \\
qrfrz & Probabilistic freezing of rain to form snow or hail \\
qsaci & Accretion of cloud ice by snow \\
qsacr & Accretion of rain by snow to form snow or hail \\
qsacw & Accretion of cloud water by snow \\
qscev & Condensation/Evaporation of vapor to/from wet snow \\
qscni & Autoconversion of cloud ice to snow \\
qsdpv & Vapor deposition to snow \\
qsfi & Bergeron process, transfer of cloud ice to snow \\
qsfw & Bergeron process, transfer of cloud water to snow \\
qsmlr & Melting of snow to rain \\
qssbv & Vapor sublimation from snow \\
qsspait & Secondary production I of cloud ice from snow \\
qsspbit & Secondary production II of cloud ice from snow \\
qvcnd & Condensation/Deposition to/on cloud water/cloud ice \\
qves & Evaporation/Sublimation of cloud water/cloud ice \\
qwfzi & Homogeneous freezing of cloud water to cloud ice \\
& \\
\hline
\end{tabular}


system. The simulation is carried out by using a three-dimensional, time-dependent, nonhydrostatic, hail parameterization model (HPM) developed by the Atmospheric Physics and Chemistry research group at the University of Wisconsin-Madison. Time evolution of this simulated convective system in general aspects can be found in Wang and Lin (1995).

The following sections describe the various aspects of microphysical processes in greater detail. Section 2 provides a brief description about the model and initial conditions for this simulation. Section 3 presents the kinematics and thermodynamic features of the simulation, and in more detail about the microphysical processes leading to the production and depletion of precipitation within the system. The final conclusions and discussions of the results are given in section 4 .

\section{METHODOLOGY}

As indicated before, the Wisconsin Dynamical/Microphysical Model (WISCDYMM) is a time-dependent, three-dimensional, non-hydrostatic cloud model cast in a quasi-compressible dynamic framework. This model includes detailed cloud microphysics and hence suitable for the investigation of cloud studies that can resolve the physics of cloud and precipitation particle ensembles. It has been applied successfully in simulating the dynamical and physical processes in thunderstorms in the US Midwest areas (Johnson et al., 1993, 1994; Straka, 1989).

The version of WISCDYMM used in this study is the Hail Parameterization Model (HPM) version in which the growth of hail and graupel are treated by parameterized expressions rather than by keeping track of the changes in different bins of particle sizes. In this version, the parameterizations of cloud physical processes are based on that of Lin et al. (1983) and Cotton et al. (1986) as explained in Straka (1989) and Wang (1996).

The microphysical processes are parameterized by the bulk method with the hydrometeors divided into five types: cloud water, cloud ice, rain drops, snow, and graupel/hail. There are 38 microphysical processes incorporated in the model including nucleation, condensation, evaporation, freezing, melting, sublimation, deposition, autoconversion and accretion. Figure 1 depicts the interactions between the water substance and the definitions of variables are described in Table 1.

The size distribution of rain, snow, and graupel/hail are assumed to follow MarshallPalmer type (exponential) distributions, while the cloud water and cloud ice are assumed to be monodispersed. The microphysical parameterizations and mass weighted mean terminal velocities are determined from such distributions. A complete description can be found in Straka (1989) and Wang (1996).

In the present study, the horizontal domain is $55 \mathrm{~km} \times 55 \mathrm{~km}$ with a $1 \mathrm{~km}$ grid spacing resolution. There are 40 grid points in the vertical domain with $500 \mathrm{~m}$ spacing from surface up to $19.75 \mathrm{~km}$. At the beginning, a bubble ${ }^{1}$ of $20 \mathrm{~km}$ wide and $4 \mathrm{~km}$ deep with $3.5^{\circ} \mathrm{C}$ thermal perturbation warmer than the surrounding environment is placed in the center of the domain with its center $2 \mathrm{~km}$ above the ground level. In order to keep the system within the $55 \times 55 \times 20$ $\mathrm{km}$ domain during the simulation, a mean horizontal wind is removed from the base-state

1 The bubble size problem is addressed in footnote 2 . 
wind profile and is adjusted every 30 minutes to accommodate changes as convective system propagates. A 3 seconds time step was used in the model simulations and the output was analyzed every two minutes.

The initial input is an adjusted sounding data as shown in Figure 2. This sounding is quite different from midlatitude severe storm cases (e.g., Johnson et al., 1993,1994). It depicts a low lifting condensation level (LCL) and free convection level (LFC) with a relative large convective available potential energy (CAPE), indicating a strongly convective-unstable atmosphere (Jou, 1994). The general synoptic condition at the time was discussed in Jou (1994) and will not be repeated here. It is to be noted that WISCDYMM does not contain the effect of topography and hence can not be used for a long time simulation where topographic effect is expected to be strong. However, for the purpose of showing microphysical features, it should produce useful results since the microphysical structure of the cloud tend to be stabilized rather quickly compared to the dynamical time scale. The radar echoes indicated that the system displayed a recurring feature of about 1.5-2 hours interval due to the topographic effect (Jou, 1994). Since the microphysical structure of the cloud in the simulation stabilizes in

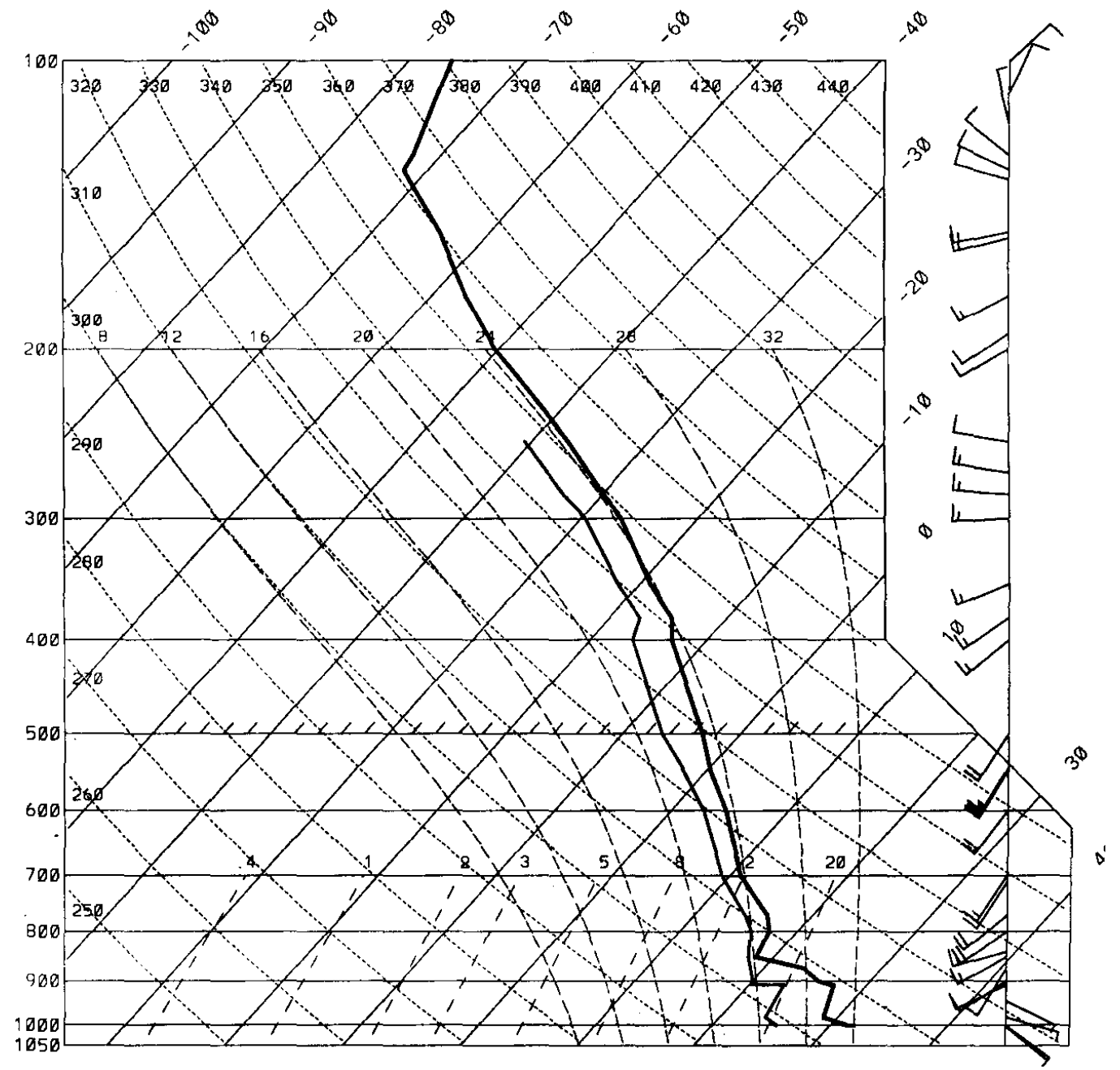

Fig. 2. The skew T-log P presentation of sounding initiated from Panchiao (44692) at 00Z, 12Z, and surface data in June 21, 1991. 
about 30-40 minutes from the beginning of the run (the spin-up time), the results should be reasonable.

In addition, the starting time $(\mathrm{t}=0)$ in a numerical simulation should not be taken as the corresponding starting time of a storm. Depending on the initialization methods, some simulations will take longer time to reach a stabilized state while others will take shorter time. In the present study we use the identical perturbation as did Johnson et al. $(1993,1994)$. This may be suitable for Midwestern severe storms in U.S. but not necessary the most suitable for East Asian subtropical storms. However, one of the purposes of the present study is to test whether the microphysical parameterizations of WISCDYMM-HPM are capable of producing reasonable results in subtropical areas that it appears to be so. We want to perform one test at one time so as not to complicate the interpretation. Thus the results presented here should be taken with this time effect in mind.

However, we are aware of the fact that the initialization technique has important impact on the storm dynamics and we plan to rum sensitivity test on this factor in the near future. Hopefully in that study we will be able to determine the suitable initialization technique for thunderstorms in Taiwan area. ${ }^{2}$

\section{NUMERICAL SIMULATIONS AND RESULTS}

\section{1. Kinematics Features of the Simulated System}

Simulated maximum vertical velocity time series in the updraft core is shown in Figure 3. A strong updraft of $54 \mathrm{~m} / \mathrm{sec}$ develops from the initial perturbation by 16 minutes and then decreases in response to the precipitation loading of the updraft. As this updraft is mainly the

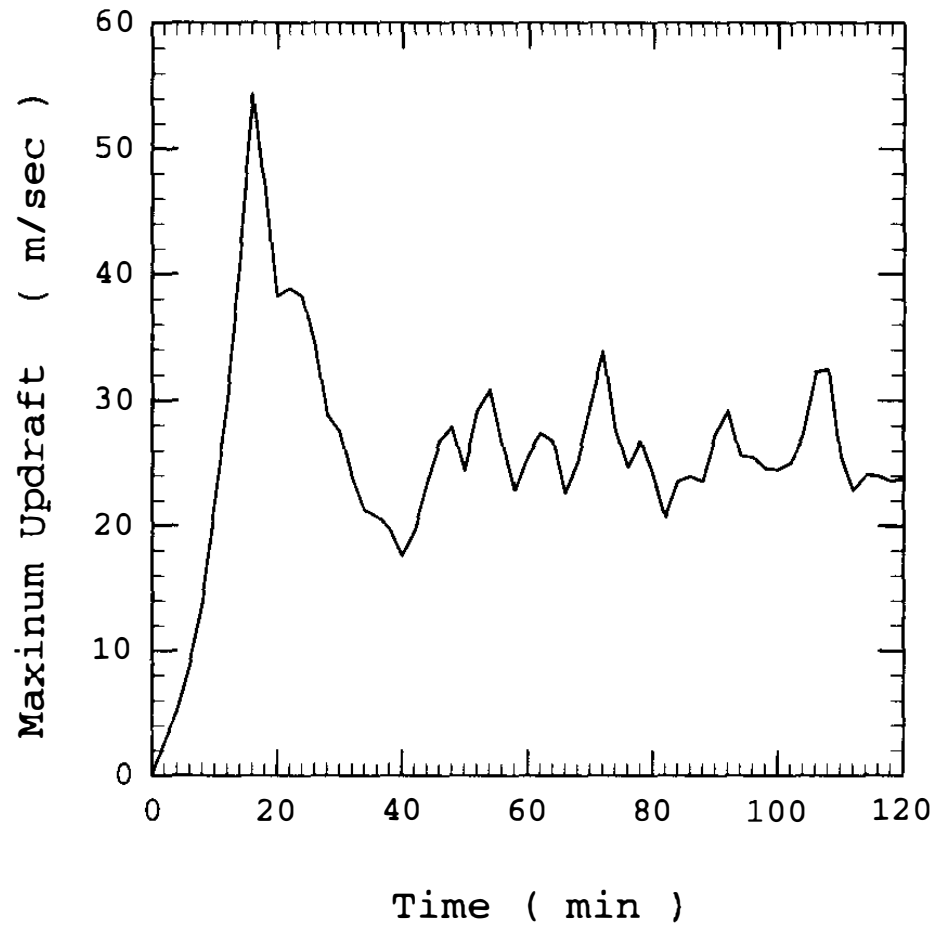

Fig. 3. Maximum updraft vs. time.

${ }^{2} A$ preliminary recent study by use shows that changing the initial perturbation to a smaller size changes the time when the system stabilizes. The system stabilizes sooner but the microphysical structure remains much the same as the present results. 
response to the initial perturbation technique, it should not be taken as an indication of the absolute maximum updraft. As shown in Figure 4, by 30 minutes, the system has developed from the initial $2 \mathrm{~km}$ altitude to an extent well above $12 \mathrm{~km}$ and rain has fallen down to the ground, while ice, snow, and graupel/hail distribute in a layer from $4 \mathrm{~km}$ to about $12 \mathrm{~km}$ above surface. Careful inspection shows that the convective system, without significant vertical shear, is developed vertically with rain region right under the region of graupel/hail. This strong spatial correlation suggests that the source of rain mainly come from the melting and shedding of graupel/hail. We will see further evidence of this in the microphysical analysis.

After 60 minutes, the areal coverage of the convective system grows larger as shown in Figure 5, but the precipitation is not as intense as in 30 minutes. In the mean time, as shown in Figure 6, when the main cell becomes weaker, the downdraft cold pool outflow and the surrounding inflow triggers new convection, causing new cells to develop and then merge to the main cell later. This phenomenon is more evident after 60 minutes as shown in Figure 7. The newly developed convection cells will not only lengthen the duration of the system but also produce significant rainfall. By examining the rain fall area in detail, we found that the rain area is concentrated within a $20 \mathrm{~km} \times 20 \mathrm{~km}$ area with a maximum intensity $37 \mathrm{~mm}$ rainfall in 10 minutes (Figure 8) similar to the $40 \mathrm{~mm}$ within 10 minutes as described by Jou (1994).

During the simulation, the ice hydrometeor does not reach the ground. They are mainly distributed from $4 \mathrm{~km}$ to about $12 \mathrm{~km}$ above ground surface as shown in Figure 5, Figure 6, and Figure 7. This is obviously due to the relatively warm air temperature in the lower layers that result in the complete melting of ice particles. Note that due to the lack of topographic effect, some of the dynamical features, such as the outflow directions, should not be taken for granted. Rain water is the only hydrometeor that reaches ground contrast to the U.S. midwestern thunderstorm: where copious hail fell to the ground. Figure 9 is the simulated rain fall rate on the ground surface in the first and second hour. The extended heavy rain fall rate in the third hour combined with the first two hours, showing a $117 \mathrm{~mm}$ rain fall in three hours, is similar to the $120 \mathrm{~mm}$ observation (Jou, 1994). We understand that this amount represents the total rainfall following the core, not the total rainfall at one fixed point. But this is because we do not include the topographic effect here. When that effect is included, it is likely that the precipitation core will recur in the same general area and will indeed generate that amount of total rainfall in that area, corresponding to the observed value. Basically, this indicates that the microphysical structure of such a storm is capable of producing this amount of rainfall if the dynamical situation allows.

\section{2. Time Dependent Behavior of Total Production of Hydrometeor Types}

The total mass of the condensed particles, including non-precipitating (cloud water and cloud ice) and precipitating (rain, snow, and graupel/hail), integrated over the entire domain with respect to time is shown in Figure 10a. The related mass percentage is shown in Figure 10b. In the beginning, the whole domain consists of $100 \%$ of cloud water until the rain drop and graupel/hail begin to form by the 6 minutes. After 6 minutes, the updraft leads to the onset of both cold and warm microphysical process. The expansion cooling of the ascending air and microphysical interactions cause the cloud water to be depleted rapidly while rain and 
21 JUNE 1991: TAIPEI

TIME (MIN) = 30.000

CLOUD WATER MIXING RATIO (G/KG)

$y(k m)=20.000$

cntr interval $=0.500$

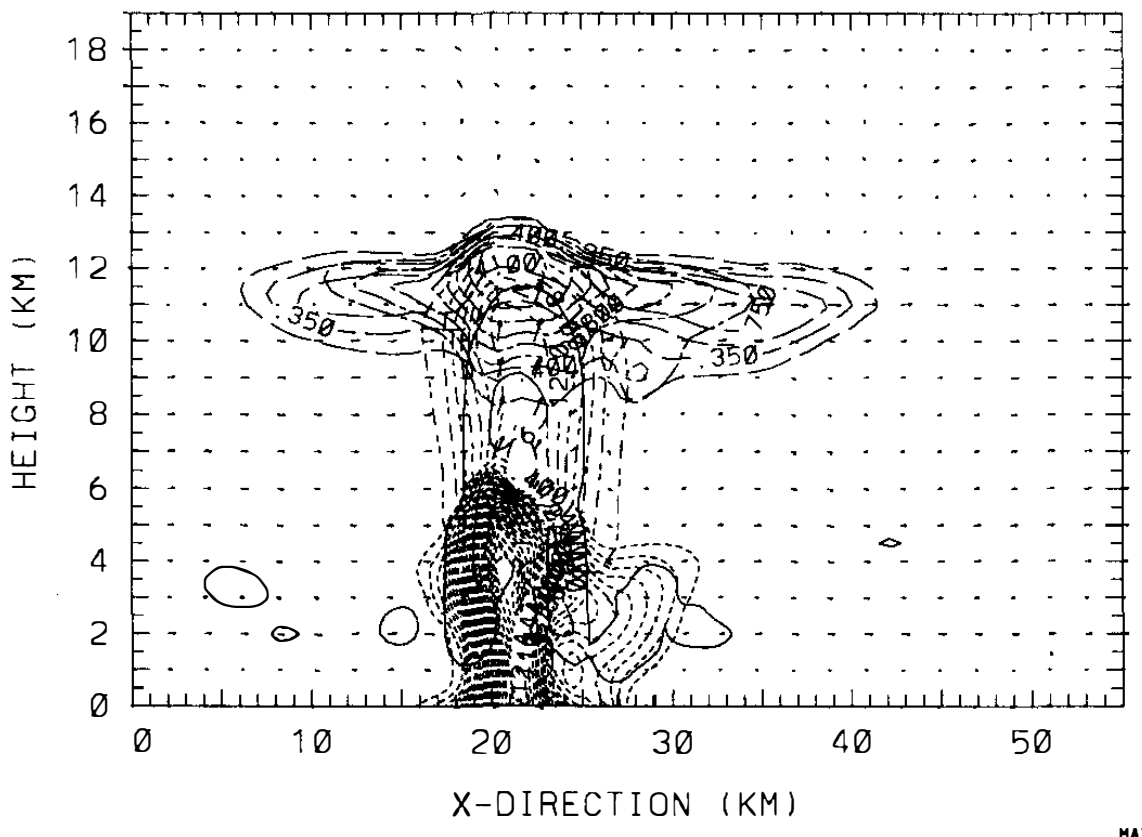

$\frac{\text { a. BagE+B2 }}{\text { MAXIAUM VIECTOR }}$

21 JUNE 1991: TAIPE I

TIME $(M I N)=30.000$

RAIN WATER MIXING RATIO (G/KG)

$z(\mathrm{~km})=0.250$

contr interval $=0.500$

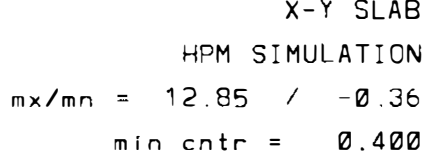



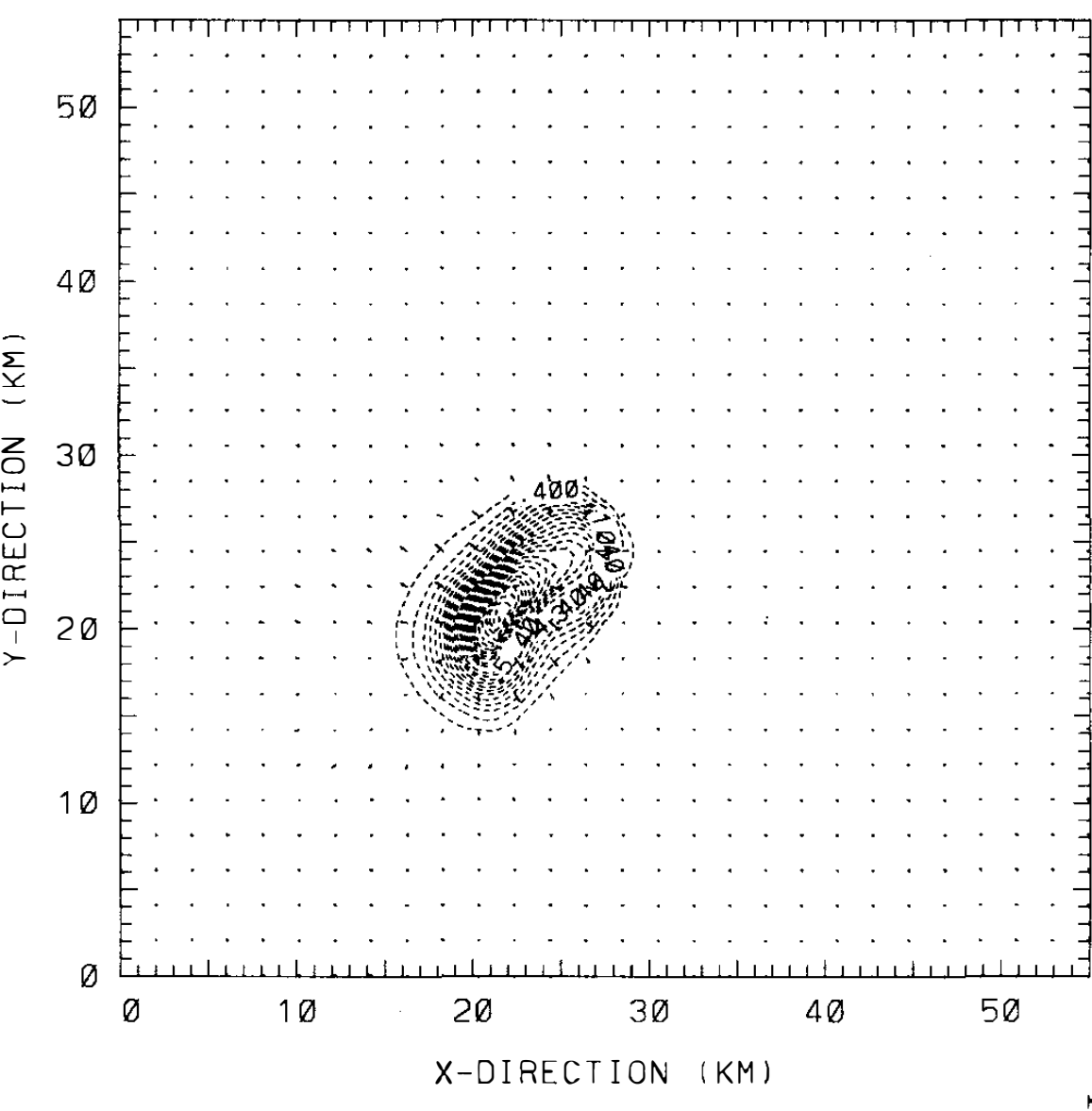

(b) (a)

Fig. 4. Simulated Hydrometeors mixing ratio of (a) the $X-Z$ slab, east-west vertical cross section, at the maximum updraft and (b) the X-Y slice, horizontal cross section, at the surface layer at 30 minutes. Long dashed lines represent mixing ratio contours of snow aggregates, solid lines for cloud water mixing ratio, dashed double dotted lines for graupel/hail, and short dashed lines for rain. 
21 JUNE 1991: TAIPEI

TIME(MIN) $=60.000$

CLOUD WATER MIXING RATIO (G/KG)

$y(k m)=24.000$
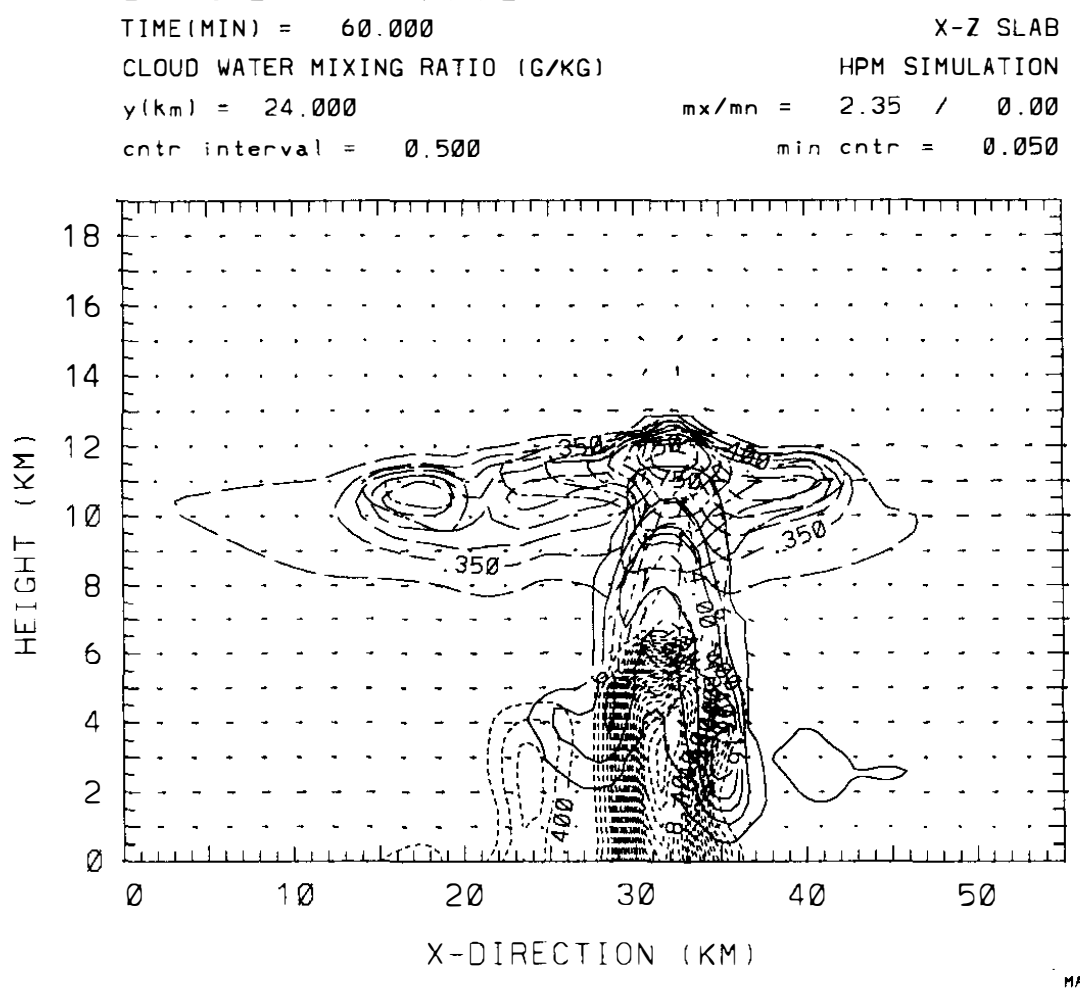

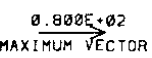

21 JUNE 1991: TAIPEI

TIME(MIN) $=60.000$

RAIN WATER MIXING RATIO (G/KG)

$X-Y$ SLAB

$z(k m)=0.250$

cntrinterval $=0.500$

HPM SIMULATION

$\mathrm{mx} / \mathrm{mn}=9.24,-0.07$

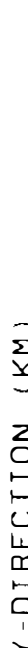

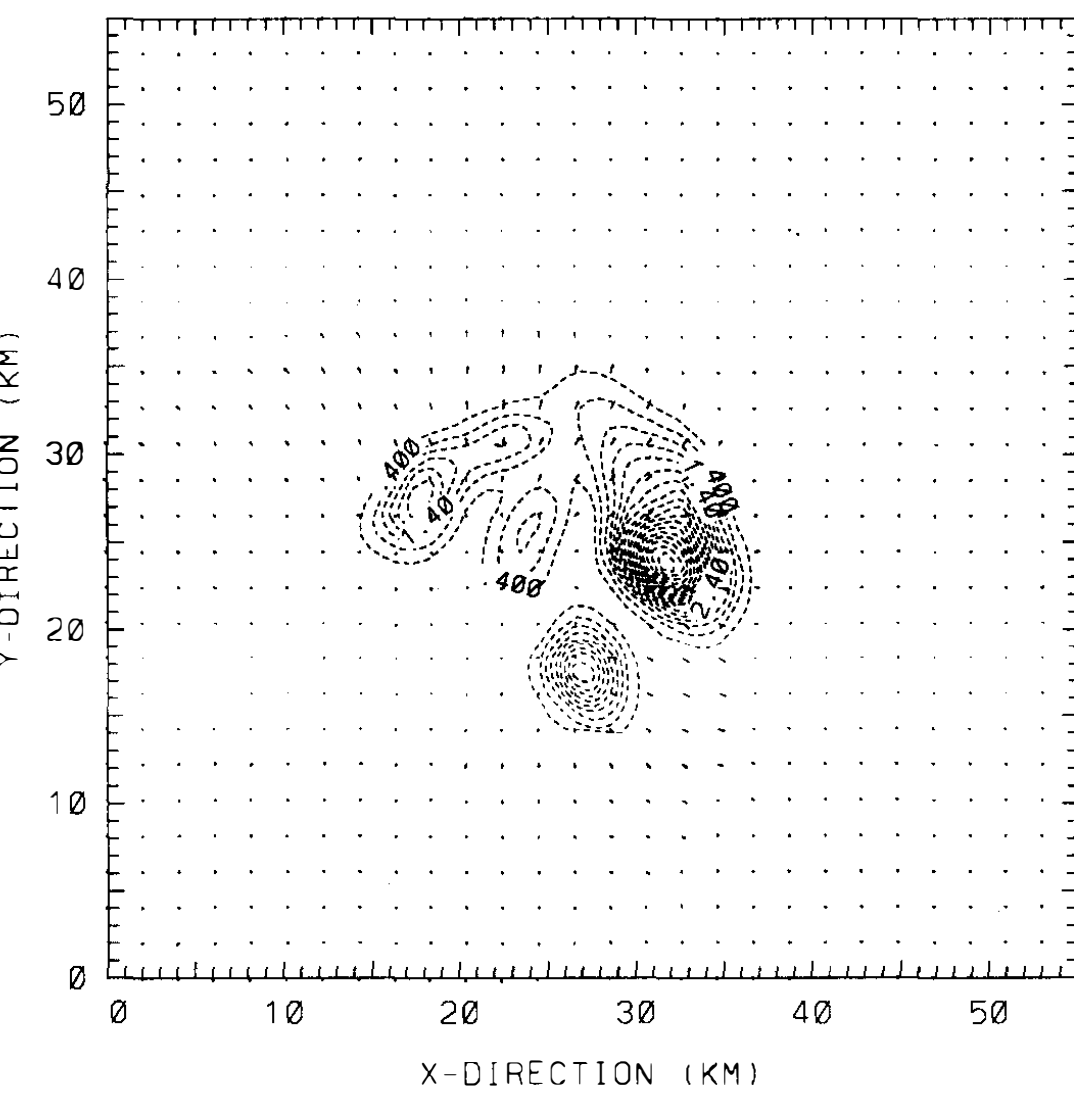

(b)
Fig. 5. Simulated Hydrometeors mixing ratio of (a) the $\mathrm{X}-\mathrm{Z}$ slab, east-west vertical cross section, at the maximum updraft and (b) the X-Y slice, horizontal cross section, at the surface layer at 60 minutes. 


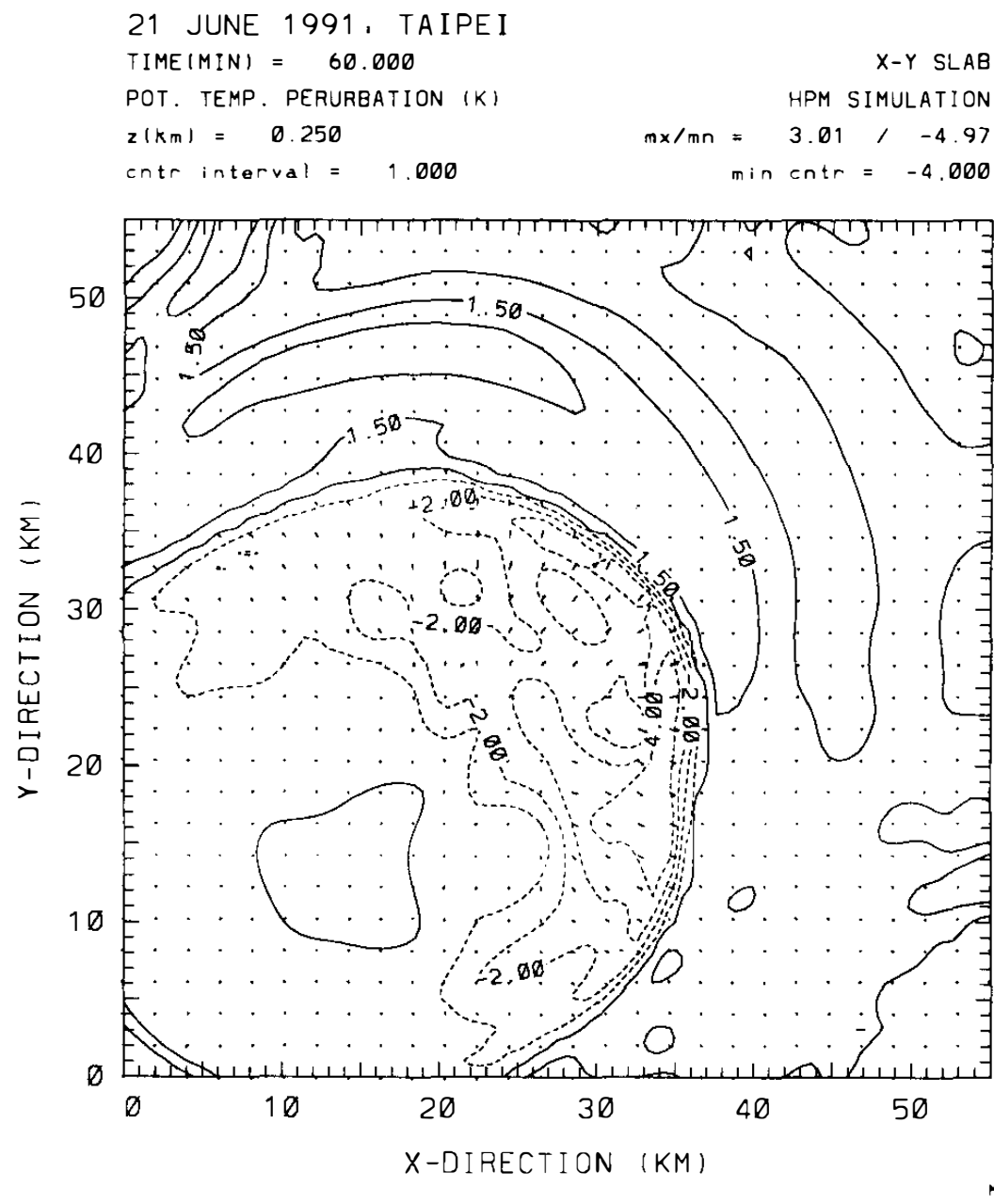

21 JUNE 1991: TAIPEI

TIME (MIN) $=60.000$ HORIZONTAL CONVERGENCE $(* 1000 / S)$

$z(\mathrm{~km})=0.250$

cntr interval $=1.000$

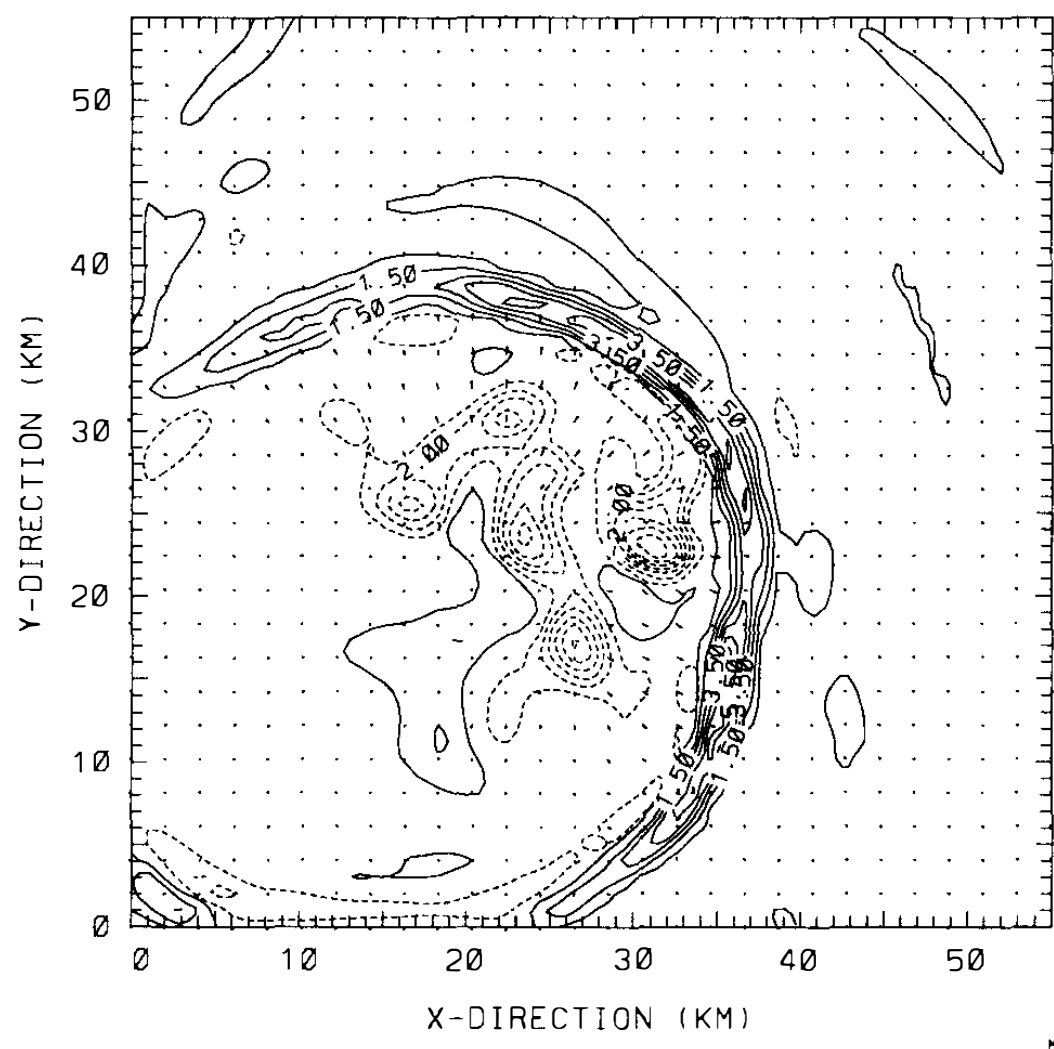

(a)

Fig. 6. Simulated (a) potential temperature perturbation (dashed curves indicate cold pool) and (b) horizontal convergence (dashed curves indicate divergent motion) at the surface layer at 60 minutes.

(b) 


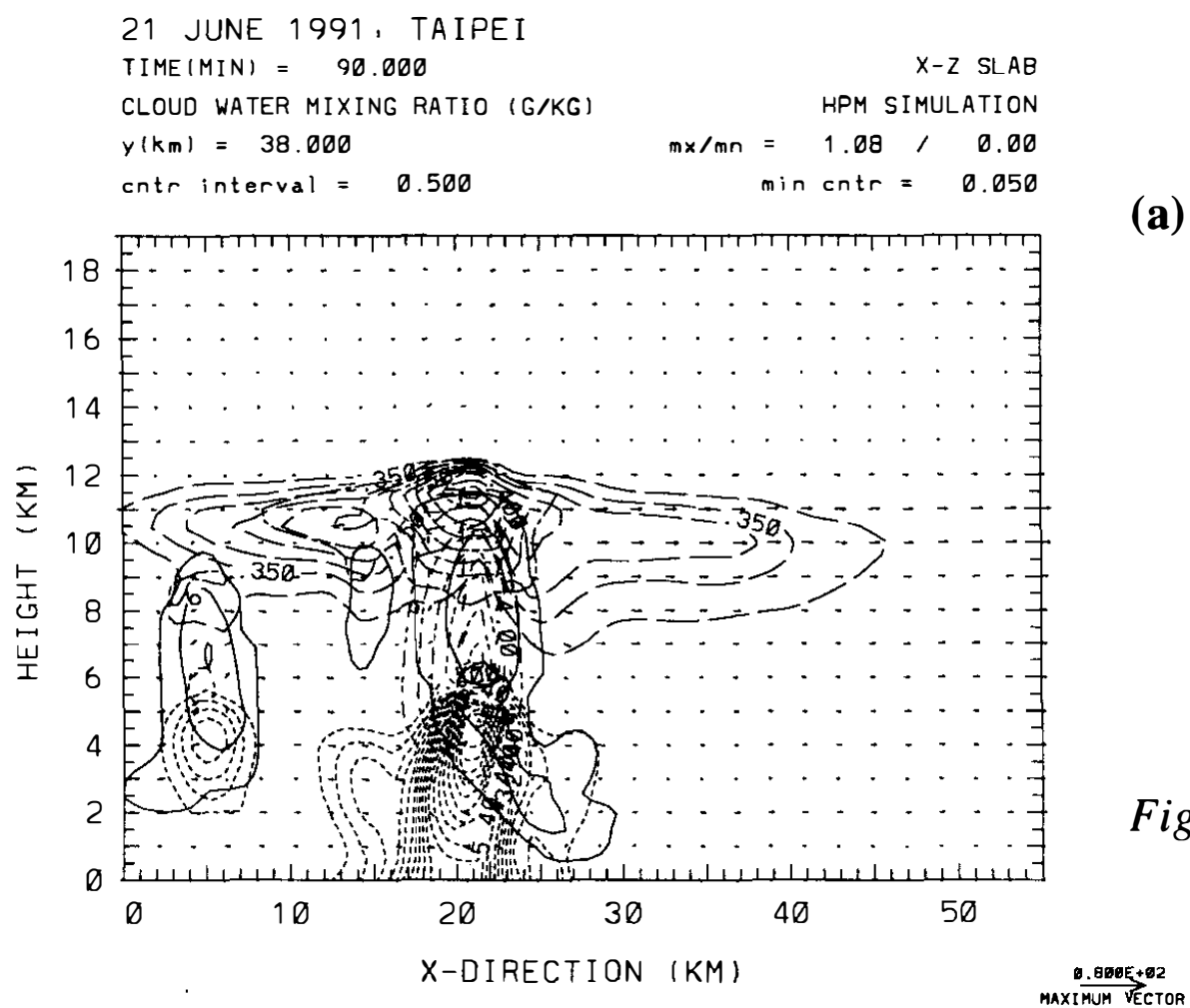

21 JUNE 1991: TAIPEI

$\operatorname{TIME}(M I N)=90.000$

RAIN WATER MIXING RATIO (G/KG)

$z \mid \mathrm{km})=0.250$
cntr interval $=0.500$

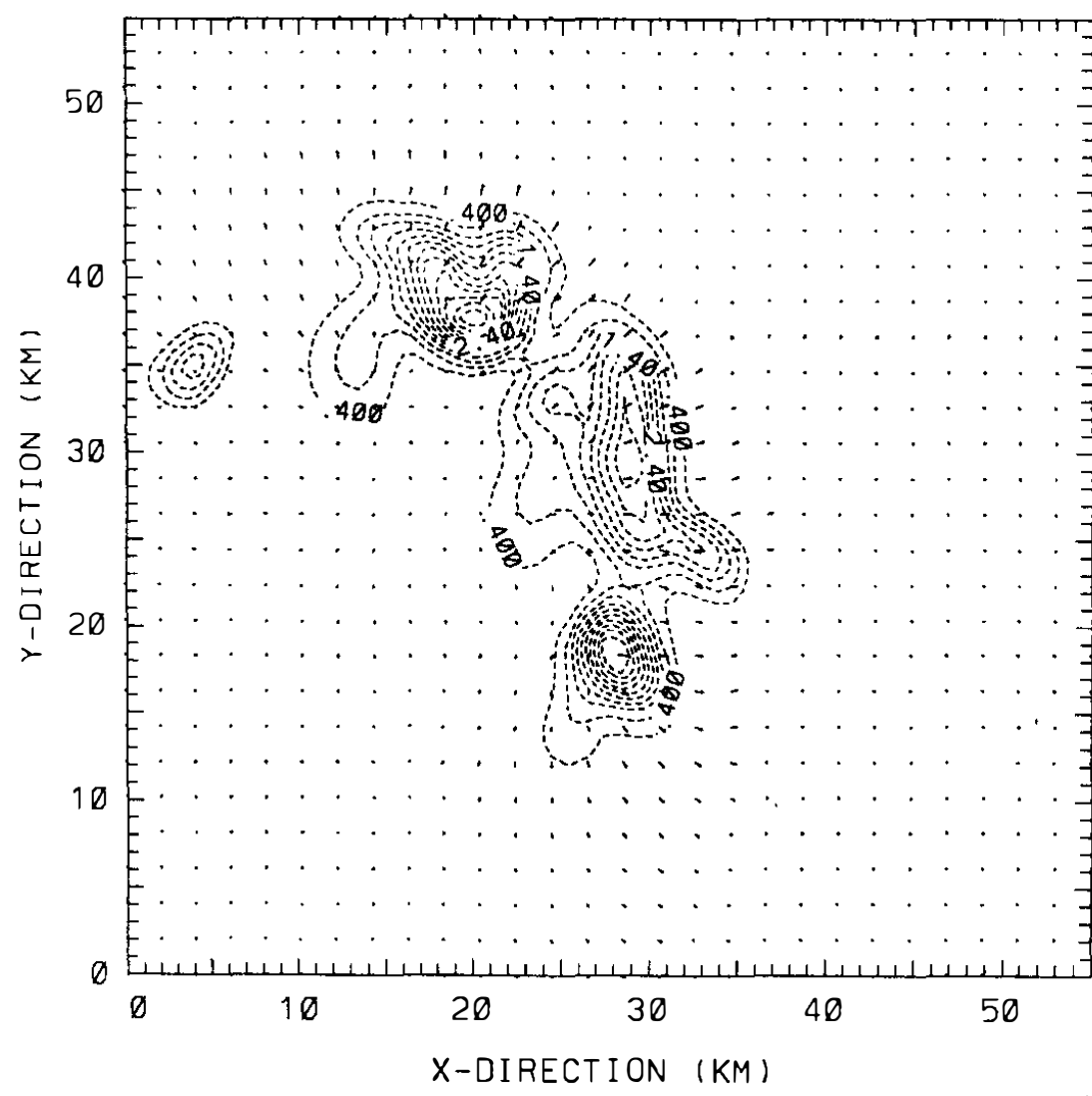

(b) (a)

Fig. 7. Simulated hydrometeor mixing ratio of (a) the $X-Z$ slab, east-west vertical cross section, at the maximum updraft and (b) the X-Y slice, horizontal cross section, at the surface layer at 90 minutes. 

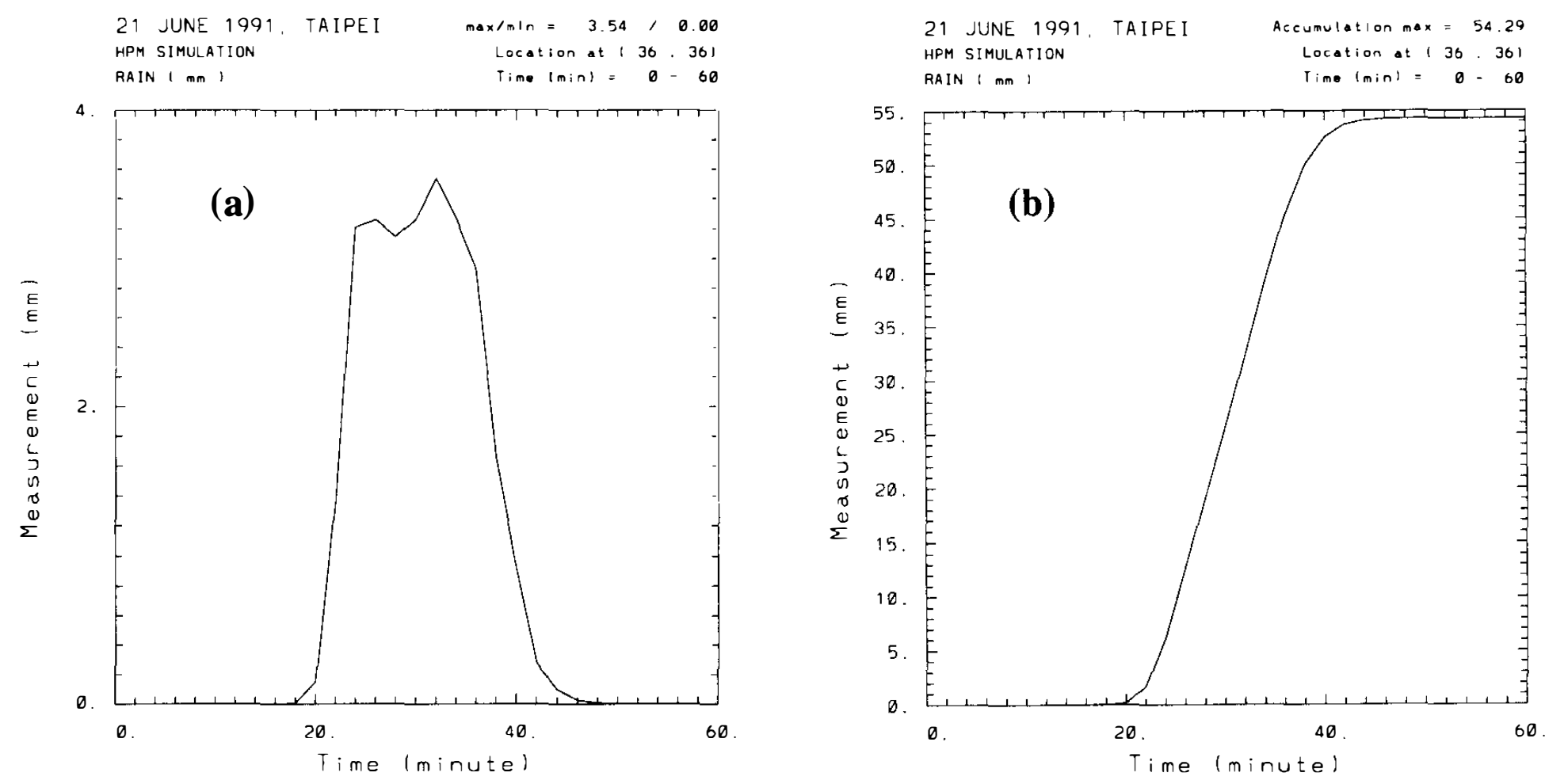

Fig. 8. (a) Specific local rainfall rate versus time (b) accumulated rainfall at the same location.
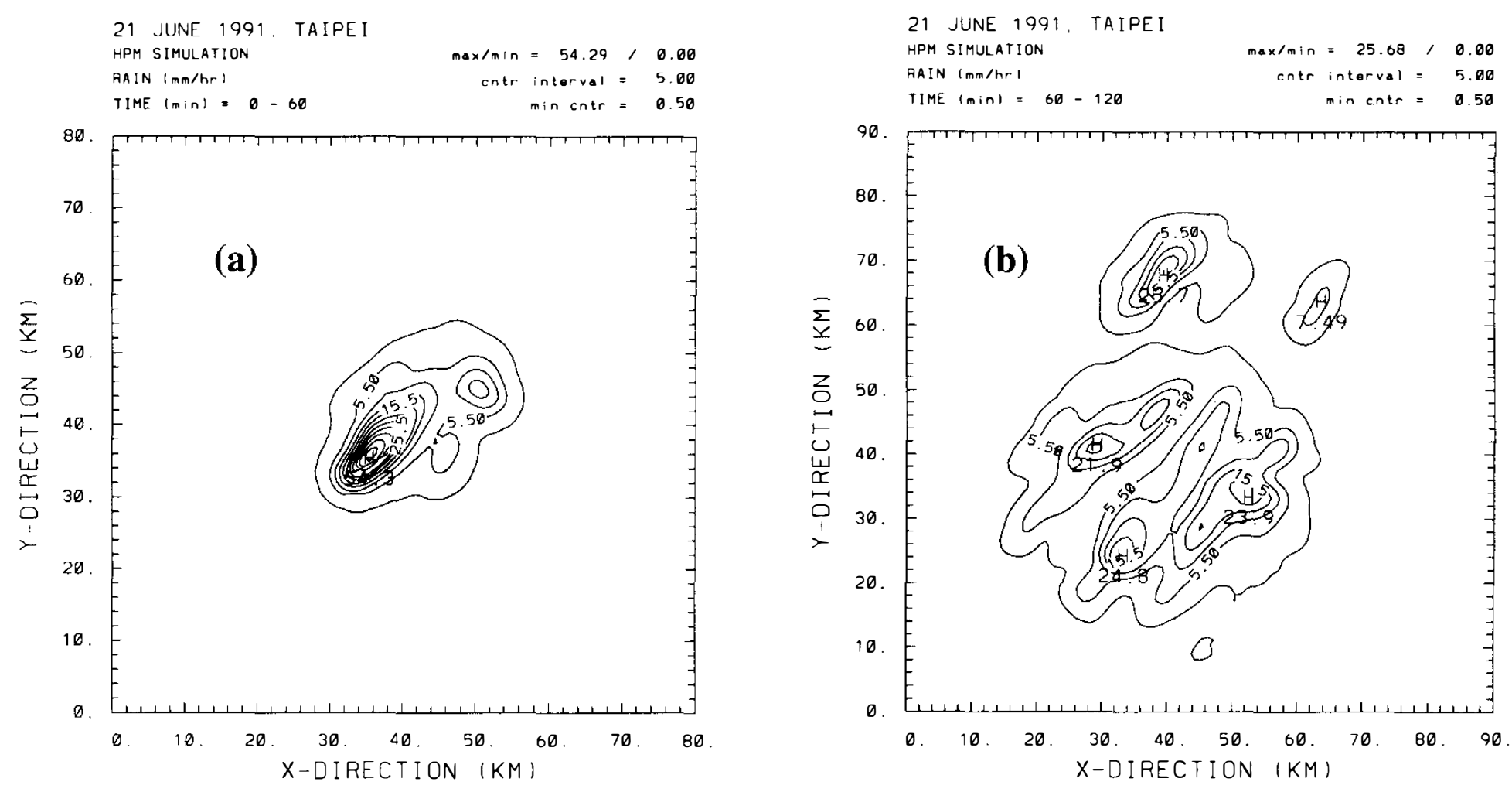

Fig. 9. Simulated rainfall rates on the surface for (a) the first hour and (b) the second hour.

graupel/hail increase rapidly more than snow and ice. As shown in Figure 10a, both graupel/ hail and rain grow initially, then decrease when the system begin to develop into quasi-steady state, and then increase rapidly again to $4000 \mathrm{KT}$ for rain and $2200 \mathrm{KT}$ for graupel/hail at 90 
minutes. Examining the mass percentage as shown in Figure 10b, we find the water phase occurred prior to the ice phase, indicating that the lower cloud region where warm microphysics exists before the cold microphysical processes are commenced in the upper cloud region. Around 20 minutes, the updraft decreases in response to the precipitation loading, graupel and hail descent from the upper level. Rain water increases rapidly from the shedding and melting of graupel/hail. The details of this are made clearer in the analysis of individual microphysical processes. The domain total mass of graupel/hail keeps decreasing until reaching the steady state at 40 minutes when the updraft becomes steady (Figure 3 ) and the relative proportion of each hydrometeor type seems to be relatively constant (Figure 10b). The steady growth of each type of hydrometeors after 40 minutes, especially rain and graupel/hail, doesn't mean the precipitation rate of each hydrometeor intensified but simply indicate the increase in the precipitating area.

Overall, after the first 40 minutes where the system reaches a steady state, the percentages of the hydrometeors in the domain are $10 \%$ for cloud water, $4 \%$ for cloud ice, $12 \%$ for snow, $30 \%$ for graupel/hail, and $44 \%$ for rain. These percentages may be considered as the characteristic microphysical structure of this storm cloud corresponding to the initial sounding profile. They may be useful in the future for rainfall forecasting by estimating the percentage of rain in the storm.

\section{3. Production and depletion processes of hydrometeors}

As we have described earlier, the system is under pure warm microphysical processes before 6 minutes. Thereafter, the ice processes begin to play an increasingly important role in the precipitation process. In order to better understand the relation shown in Figure 10, it is beneficial to examine the time evolution of individual microphysical processes contributing to the production and depletion of hydrometeors.
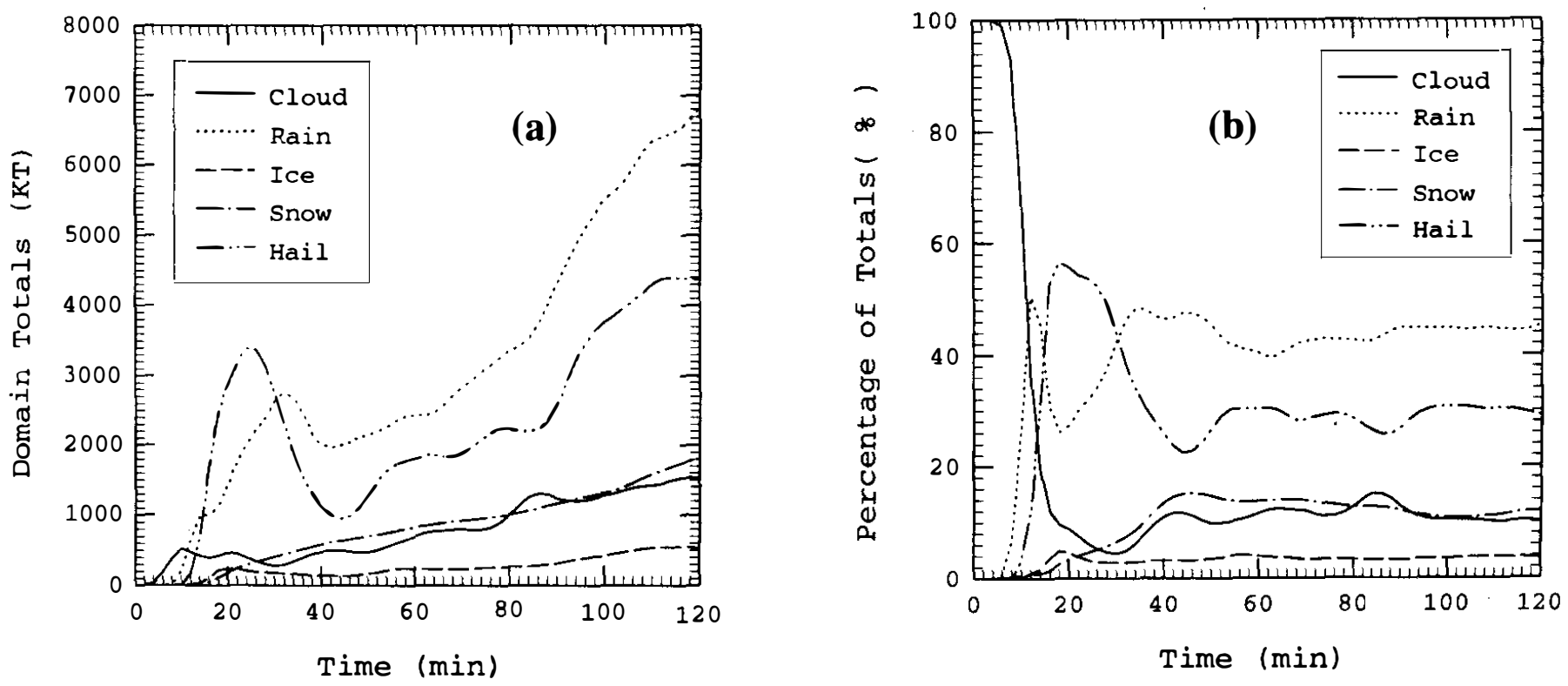

Fig. 10. Time evolution of domain total (a) mass (in kilo-ton unit) and (b) percentage of cloud and precipitation particles in simulation. 
(1) Rain

Figure 11 shows the individual processes that contribute to the rain production. There are 6 processes involved, but the melting of snow and shedding of collected, but unfrozen cloud water during the melting of snow can be neglected as they contribute less than $1 \%$ of the total. Figure. $11 \mathrm{~b}$ shows that the warm microphysical processes, accretion and autoconversion of cloud water, dominate in the early 10 minutes until the ice-phase occurs. The expansion cooling due to rising air causes pure vapor phase to change, thus the amount of autoconversion decrease followed by increased accretion. Around 16 minutes, the updraft resulted from the initial perturbation decreases in response to the precipitation loading. At the same time, the heavy ice hydrometeors, graupel and hail, fall to lower levels, melt and shed rain water. By comparing with Figure 10a, it is seen that the peak rain water production from melting and shedding of graupel/hail occurs approximately 5 minutes later than the total graupel/hail maximum. This time lag is apparently the time required for graupel/hail in the mid-level to reach the melting level. This changes greatly the relative importance of rain-producing mechanisms. Thus, the rain production due to collision and coalescence, qracw, abruptly decreases from $80 \%$ at 10 minute to $10 \%$ at 30 minutes, then remains steady around $22 \%$ at the remaining simulation time. After 10 minutes, the rain source is gradually dominated by the shedding of graupel/hail (50\% average) and melting of graupel/hail (25\% average) . Overall, we can see that the general melting process of graupel/hail contributes as the largest source $(75 \%)$ for the rain production.
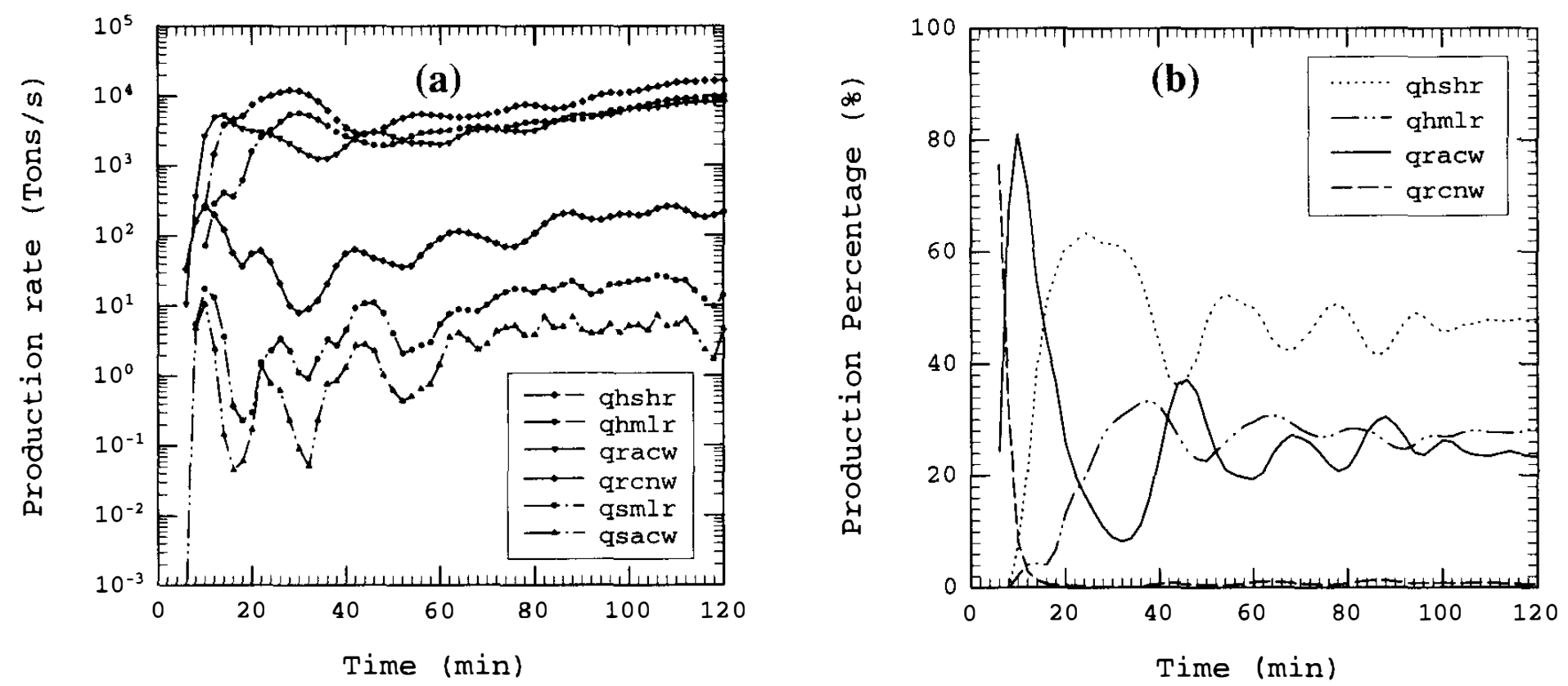

Fig. 11. Production rates of rain, integrated over the entire domain, as a function of time. A key to the process acronyms is shown in Table 1. (a) mass production rate $(b)$ percentage production rate.

As shown in Figure 12, accretion of supercooled raindrops by ice to form snow and graupel is the main sink for rain water in the initial 10 minutes, but it loses its dominance quickly as the graupel/hail grows. After the first 20 minutes, the large number of graupel/hail particle accreting rain water contributes as the largest sink for rain depletion. On the average, this 
process counts as $70 \%$ of the total rain water depletion rate. The next largest sink, accounting for $20 \%$ of the total rain water depletion rate, is the evaporation of rain. The other $10 \%$ of rain water depletion are caused by the accretion of rain by snow to form graupel/hail and accretion of rain by ice to form snow and graupel. Closer inspections of the curve reveals that the accretion by snow and graupel/hail seem to have the same depleting pattern. Because of the smaller amount of snow being produced, as shown in Figure 10, and the relative smaller collision efficiency of rain than the graupel/hail, the accretion by snow (4\%) is far less than that of graupel/hail (70\%).

(2) Snow

Figure 13 shows the time evolution of individual microphysical processes contributing to the production of snow. It includes 10 processes as shown in Figure 13a. Those processes that are two orders of magnitude smaller than the primary sources can be considered as of little importance to the production of snow and hence will not be considered further. Figure 13b shows that the greatest mass increase in snow occurs due to the Bergeron process that transforms cloud ice to snow. The amount increases significantly after 10 minutes and reach to more than $80 \%$ around 20 minutes. After reaching the steady state at 40 minutes, the contribution of this process, qsfi, accounts for $70 \%$ of the total snow production. The second largest snow production process is snow accreting cloud water in the higher liquid water content region of the updraft, reaching its maximum $45 \%$ of the total snow production at the initial 10 minutes as shown in Figure 10, and decreases after that to about $18 \%$ for the remaining time. Vapor deposition occurs primarily in the updraft region where supersaturation with respect to ice is the greatest. After 40 minutes, it is the third largest production mechanism with $6 \%$ contribution. The other three minor mechanisms, snow accrete rain water and cloud ice, and cloud ice accrete rain water, combined to represent only $6 \%$ for the amount of snow production.
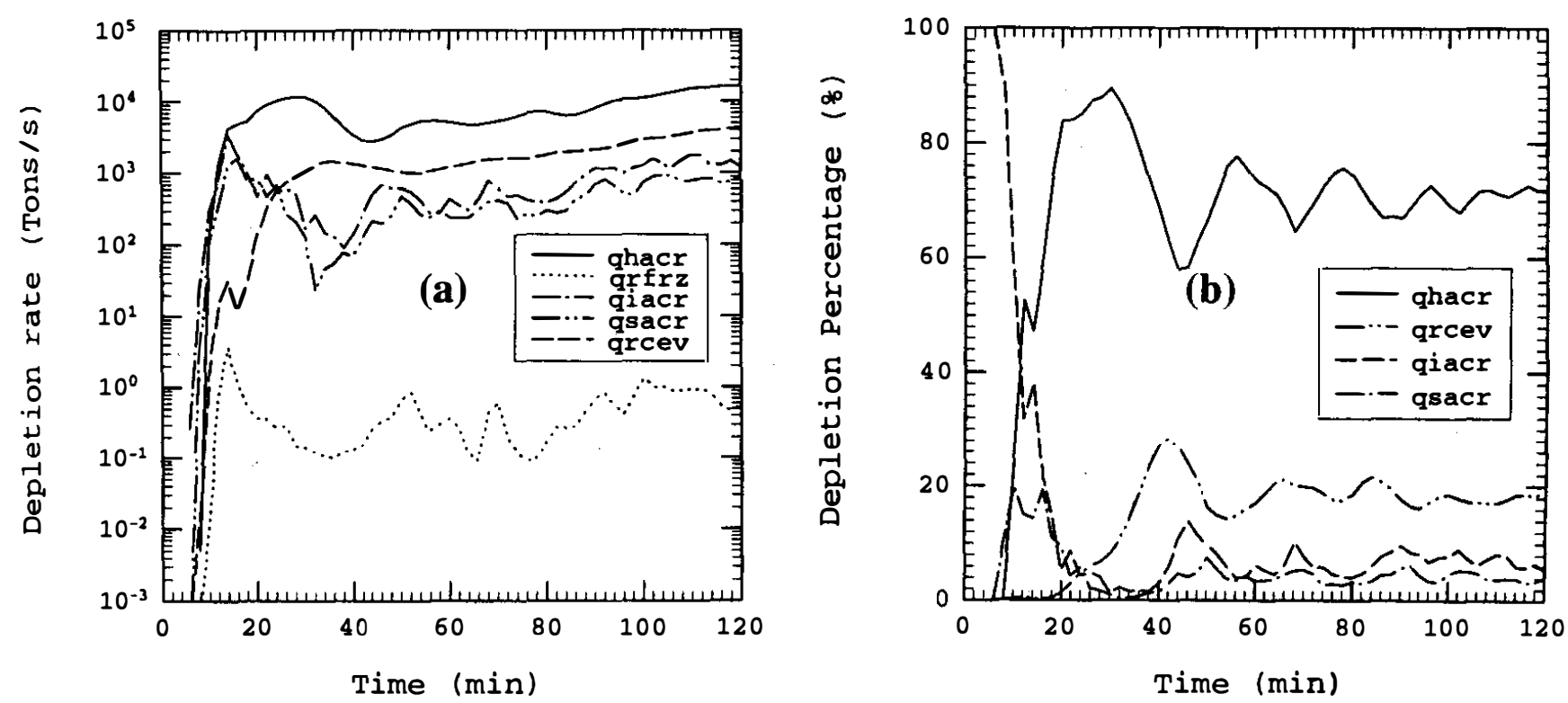

Fig. 12. Depletion rates of rain, integrated over the entire domain, as a function of time. A key to the process acronyms is shown in Table 1. (a) mass production rate (b) percentage production rate. 
Since rain and graupel/hail are the two most abundant hydrometeors in the simulation (Figure 10) and snow mainly occurs above the $0^{\circ} \mathrm{C}$ isotherm level with a low terminal velocity, it is evident from Figure 14 that the main mechanism of snow loss is due to the accretion of graupel/hail which account for $85 \%$ of the total snow depletion rate after 20 minutes. Sublimation, accounted for $14 \%$ overall, is the second largest sink of snow and is primarily occurring in and below the outflow anvil. Accretion of snow by rain to form graupel/hail in the lower region of cloud near $0^{\circ} \mathrm{C}$ isotherm and the melting of snow below the melting level are only operating in the first 16 minutes and after that they only contribute to a mere $1 \%$ of total snow depletion.

(3) Graupel/hail

In previous sections, we see that the graupel and hail play an important role in the production and depletion of rain water and depletion of snow. As shown in Figure 15a, accretional growth, including accretion of rain, cloud water, and snow, is the major growing process for graupel/hail. Direct accretional growth by graupel/hail is the dominating process accounting for $90 \%$ of total graupel/hail production rate after reaching the steady state at 40 minutes, while accretion of rain by cloud ice and snow to form graupel/hail and accretion of snow by rain to form graupel/hail account for the other $10 \%$ of total graupel/hail production rate. After reaching the steady state at 40 minutes, the largest production rate is associated with the accretion of rain water in the lower region of the cloud that accounts for approximately $60 \%$ of the total. It is evident that this process follows a trend nearly identical to the time evolution of rain water, as shown in Figure 10a, corresponding to the mass production of rain water at that time. Accretion of cloud water by hail is the second largest source and accounts for $20 \%$ of total graupel/hail production rate at steady state. As the volume and water content of cloud water are directly related to the updraft intensity, a similar trend for the time evolution of maximum updraft (Figure 3) can be seen. Accretion of snow produces about $10 \%$ of the graupel/hail. This is mainly due to the relatively small amount of snow produced (Figure 10) and the low collection efficiencies of hail and snow at the cold temperature where snow is most abundant, similar to that occurred in a supercell storm occurred in the US Midwest (Johnson et al., 1994). The indirect accretion growth processes, followed by the supercooled condition, increases with time as the convective system strengthens and reach a maximum combined rate $80 \%$ at 8 minutes when rain droplet are carried higher into the colder region of the convective system, while maintain a steady $10 \%$ of total production rate of graupel/hail for the remaining time.

As described previously, the shedding and melting of graupel/hail is the major mechanism of rain production (about $75 \%$ ) as shown in Figure 11. Since rain is the largest hydrometeor category produced in this simulation (Figure 10), it is evident that the main depletion mechanism of graupel/hail is the shedding of liquid layer and melting of graupel and hail into raindrops as shown in Figure 16. The greatest depletion is due to the shed of water from hail during wet growth, accounted for a maximum of $90 \%$ at 16 minutes and around $62 \%$ at steady state. Melting of hail to rain water, followed by the decrease of maximum updraft in responding to the loading of hydrometeors, increases from $6 \%$ at 16 minutes and to around $37 \%$ at steady state. Away from the updraft, sublimation of hail accounts for merely $1 \%$ of the depletion rate of graupel/hail. 

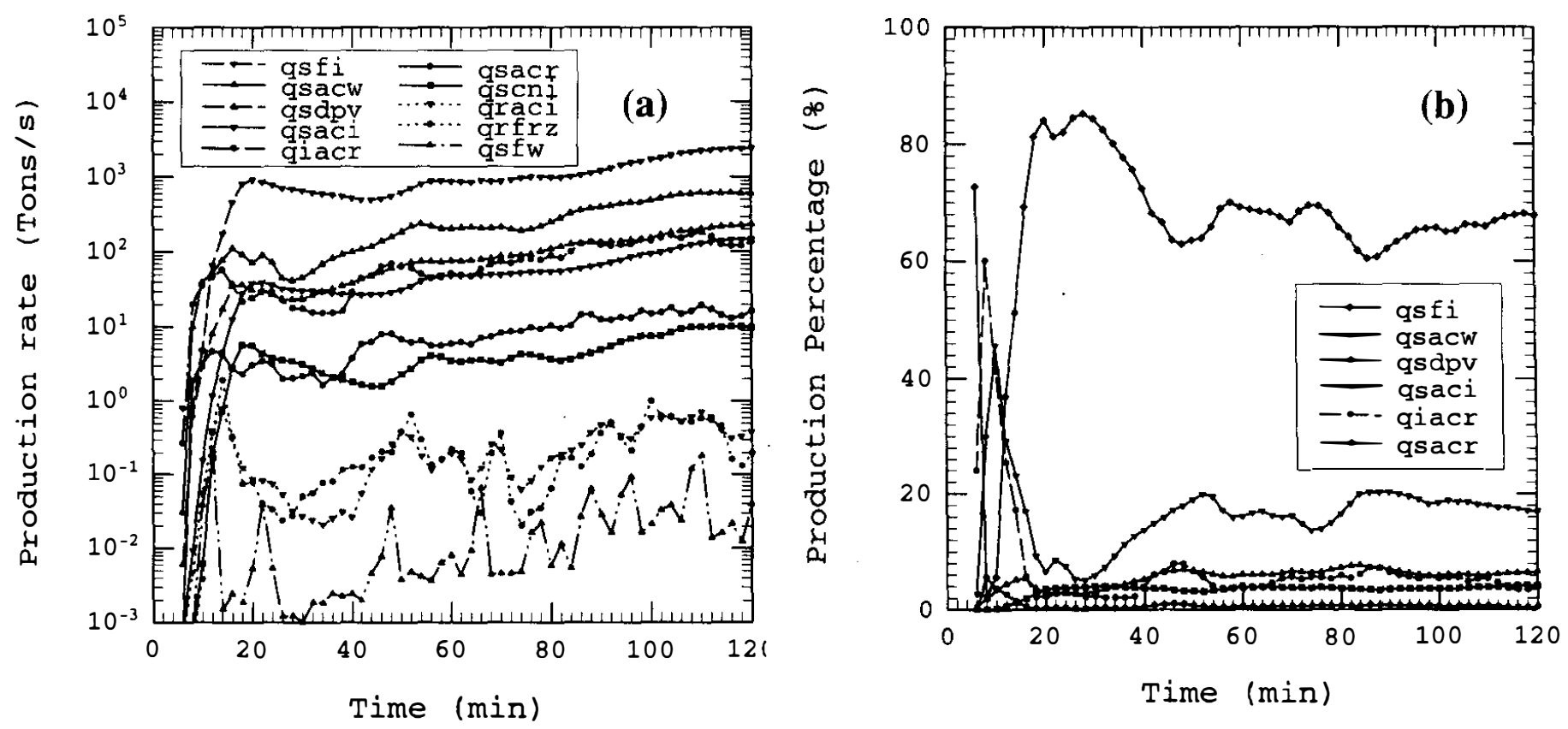

Fig. 13. Production rates of snow, integrated over the entire domain, as a function of time. A key to the process acronyms is shown in Table 1. (a) mass production rate (b) percentage production rate.
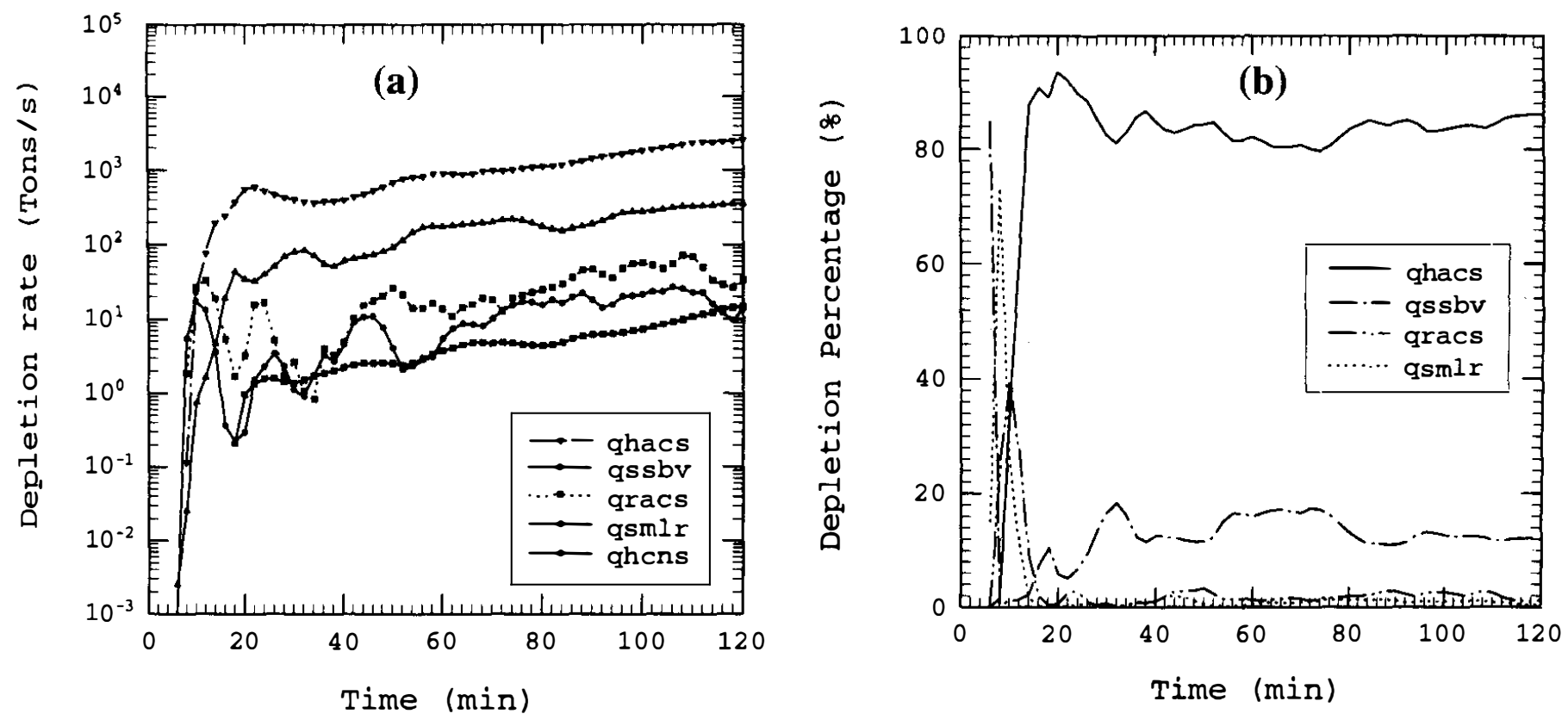

Fig. 14. Depletion rates of snow, integrated over the entire domain, as a function of time. A key to the process acronyms is shown in Table 1. (a) mass production rate (b) percentage production rate. 

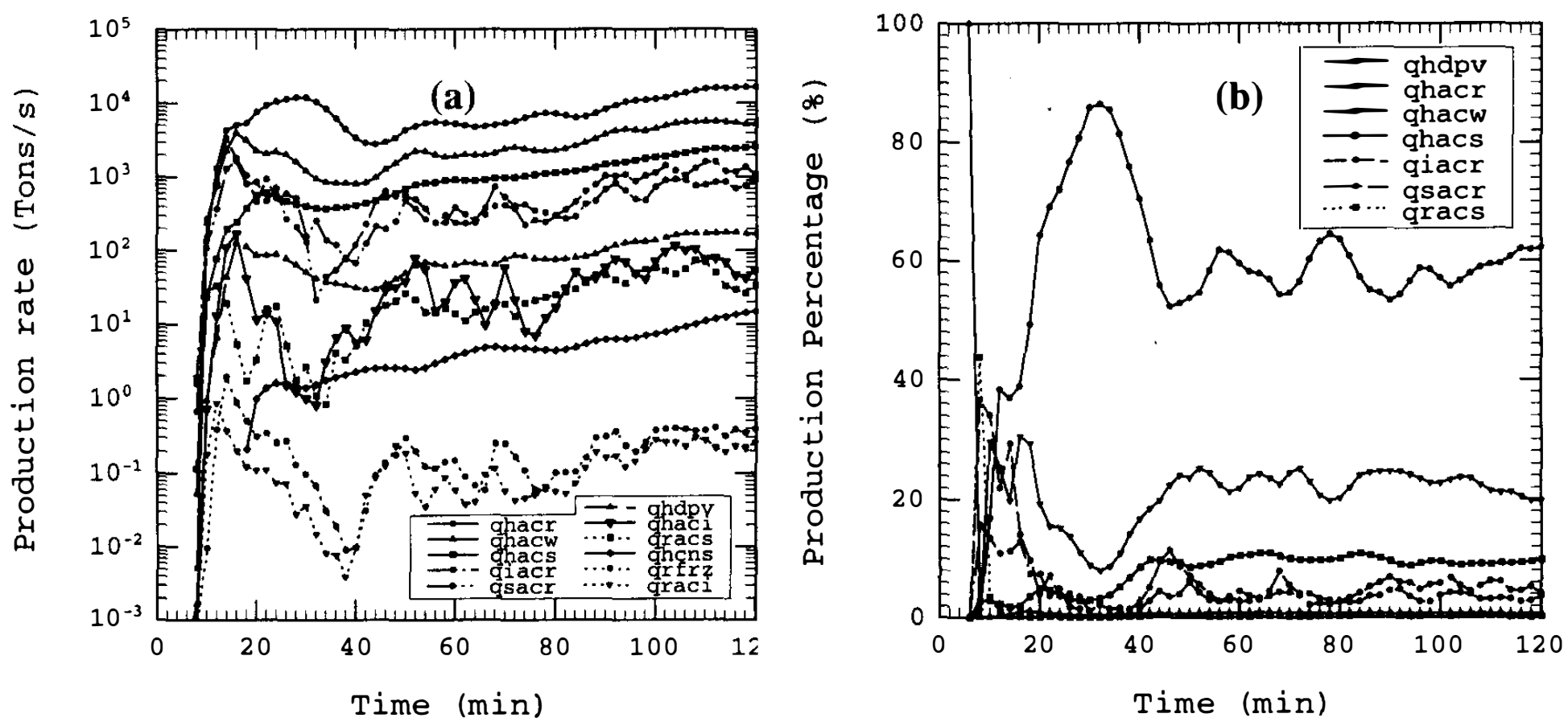

Fig. 15. Production rates of graupel/hail, integrated over the entire domain, as a function of time. A key to the process acronyms is shown in Table 1. (a) mass production rate $(b)$ percentage production rate.
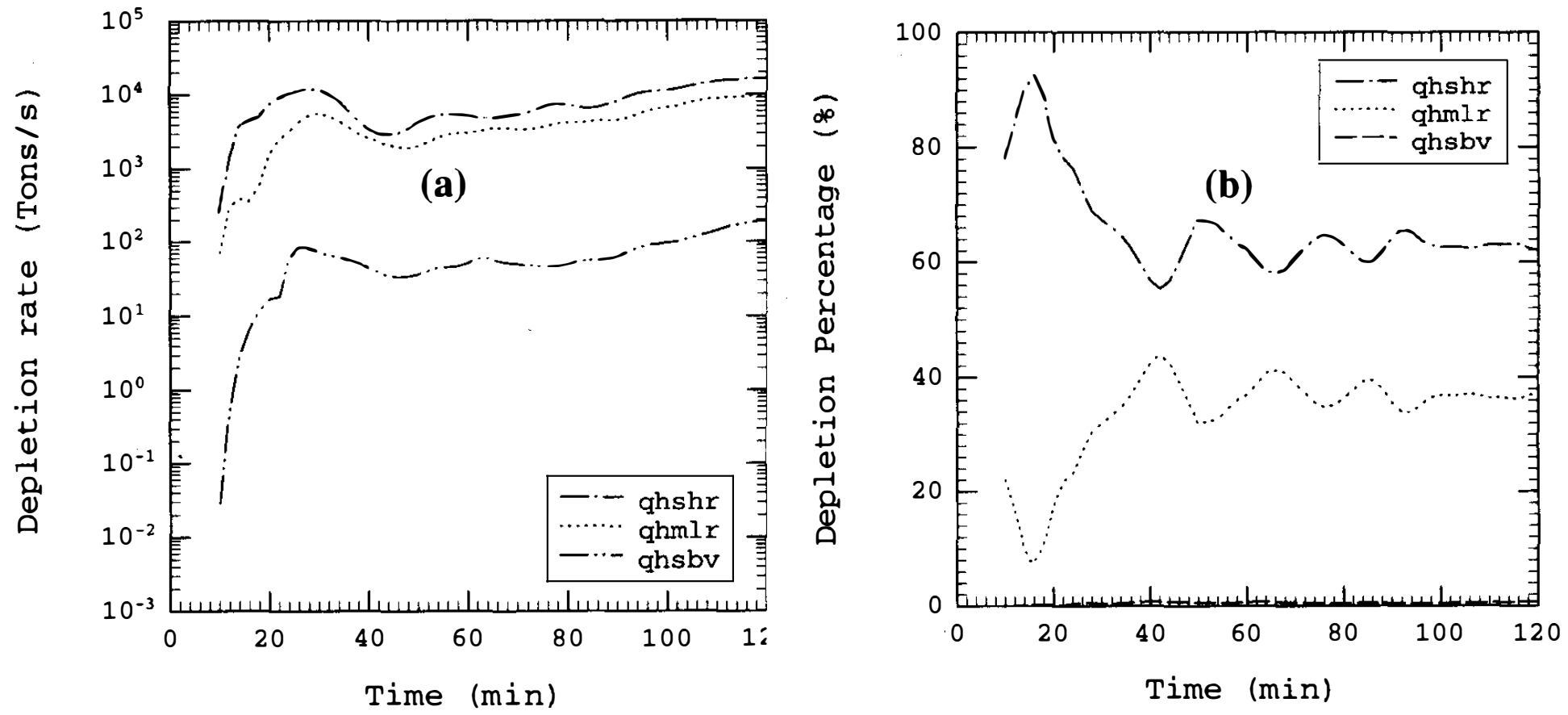

Fig. 16. Depletion rates of graupel/hail, integrated over the entire domain, as a function of time. A key to the process acronyms is shown in Table 1. (a) mass production rate $(b)$ percentage production rate. 


\section{CONCLUSIONS}

It appears that the microphysical structure of a sub-tropical convective system in Taipei area can be simulated successfully by the HPM version of WISCDYMM. Examination of the microphysical results for the precipitating hydrometeors show that not only cloud and rain water but snow and graupel/hail appear in the simulation. The overall rainfall intensity and accumulated rain is similar to the observation if the storm is given the proper dynamical steering. The liquid and ice phase each occupied about $50 \%$ of the simulated domain total hydrometeor mass. Rain water is the only hydrometeor that reaches the surface. Due to the relatively high temperature of the cloud base environment in the subtropical region, snow, ice, and grau$\mathrm{pel} /$ hail would have melted completely before they reach the ground. This is basically in agreement with the observation.

The model results strongly suggest that both cold and warm precipitation processes occur in this subtropical convective cloud system, in contrast to some previous commonly held notion that only warm rain process operates in these clouds. Moreover, the melting of graupel/ hail and shedding of the resulting liquid serve as the largest source of rain water, a fact worthwhile keeping in mind especially for the purpose of cloud seeding.

Though the overall results seem to agree with the observation, more sensitivity studies are necessary to understand model behavior. In addition, since the microphysical parameters of WISCDYMM is based on observations in the mid-latitude (Johnson et al., 1993, 1994; Straka, 1989), it will be beneficial if more cloud physical observations in Taiwan area can be made to check the parameterizations for better and more accurate simulations. Since the present version of WISCDYMM is initially developed for the Great Plains in US it has not considered the effect of topography yet. But for a long period simulation in Taiwan area where there is a complicated topography, the model needs to include this effect. Initial steps are being taken toward fulfilling this goal.

Acknowledgments This work is partially supported by U.S. NSF Grant ATM-9314465, ATM-9633424, and research contracts of Central Weather Bureau CWB-84-3M-05 and 853M-01. We thank Mr. Chang-Keng Hsiao of CWB for providing the original data, Dr. MingDean Cheng, Director of CWB's R\&D Center for encouragement, and Prof. Ben Jou of National Taiwan University for helpful comments. In addition, HML would like to thank Johnson Wax Co. of Wisconsin, U.S.A. for providing a distinguished Fellowship, and PKW would like to thank Alexander von Humboldt Foundation of Germany for the Senior Research Humboldt Award he received which partially contributed to this work.

\section{REFERENCES}

Cotton, W. R., M. A. Stephens, T. Nehrkorn, and G. J. Tripoli, 1982: The Colorado State University three-dimensional cloud model-1982. Part II: An ice phase parameterization. J. Rech. Atmos., 16, 295-320.

Cotton, W. R., G. J. Tripoli, R. M., and E. A. Mulvihill, 1986: Numerical simulation of the effects of varying ice crystal nucleation rates and aggregation processes on orographic 
snowfall. J. Clim. Appl. Meteorol., 25, 1658-1680.

Fu, Q., S. K. Krueger, and K. N. Liou, 1995: Interactions of radiation and convection in simulated tropical cloud clusters. J. Atmos. Sci., 52, 1310-1328.

Johnson, D. E., P. K. Wang, and J. M. Straka, 1993: Numerical simulations of the 2 August 1981 CCOPE supercell storm with and without ice microphysics. J. Appl. Meteorol., 32, 745-759.

Johnson, D. E., P. K. Wang, and J. M. Straka, 1994: A study of microphysical process in the 2 August 1981 CCOPE supercell storm. Atmos. Research, 33, 93-123.

Jou, J. D., 1994: Mountain-originated mesoscale precipitation system in northern Taiwan: a case study 21 June 1991. Terres. Atmos. Ocean. Sci., 5, 169-197.

Klemp, J. B., and R. B. Wilhelmson, 1978: The simulation of three-dimensional convective storm dynamics. J. Atmos. Sci., 35: 1070-1096

Kruger, S. K., 1988: Numerical simulation of tropical cumulus cloud and their interaction with the subcloud layer. J. Atmos. Sci., 45, 2221-2250.

Lin, Y.L., R. D. Farley, and H. D. Orville, 1983: Bulk parameterization of the snow field in a cloud model. J. Clim. Appl. Meteorol., 22, 1065-1092.

McCumber, M., W. K. Tao, J. Simpson, R. Penc, and S. T. Soong, 1991: Comparison of icephase microphysical parameterization schemes using numerical simulations of convection. J. Appl. Meteor., 30, 985-1004.

Ogura, Y., and T. Takahashi, 1971: Numerical simulation of the life cycle of a thunderstorm cell. Monthly Weather Review, 99, 895-911.

Pruppacher, H. R., and J. D. Klett, 1978: Microphysics of Clouds and Precipitation. Reidel, Boston, 714pp.

Straka, J. M., 1989: Hail growth in a highly glaciated central High Plains multi-cellular hailstorm. Ph.D. Diss., Dep. Meteorology, University of Wisconsin, Madison, 413 pp.

Tao, W. K., J. R. Scala, B. Ferrier, and J. Simpson, 1995: The effect of melting processes on the development of a tropical and a mid-latitude squall line. J. Atmos. Sci., 52, 19341948.

Tao, W. K., J. Simpson, and S. T.Soong, 1991: Numerical simulation of a subtropical squall line over the Taiwan strait. Mon. Wea. Rev., 119, 2699-2723.

Wang, P. K., and H.- M. Lin, 1995: A Study on the Parameterization of Cloud Physical Model for Taiwan Area. CWB84-3M-05 report (in Chinese).

Wang, P. K., 1996: Cloud Physics, National Bureau of Compilation and Translation, Taipei, $382 \mathrm{pp}$ (in Chinese) 